

\title{
Cardiac diseases in pregnancy: A 10-year review in a tertiary hospital in South-west Nigeria \\ Owojuyigbe $\mathrm{AM}^{* 1}$, Adenekan $\mathrm{AT}^{1}$, Ijarotimi $\mathrm{AO}^{2}$, Sowemimo $\mathrm{O}^{2}$, Awowole $\mathrm{IO}^{2}$, Owojuyigbe $\mathrm{TO}^{3}$
}

1Department of Anaesthesia and Intensive Care, Obafemi Awolowo University/Obafemi Awolowo University Teaching Hospitals Complex, Ile-Ife. Osun State.

${ }^{2}$ Department of Obstetrics, Gynaecology and Perinatology, Obafemi Awolowo University/Obafemi Awolowo University Teaching Hospitals Complex, Ile-Ife. Osun State.

${ }^{3}$ Department of Haematology and Immunology, Obafemi Awolowo University/Obafemi Awolowo University Teaching Hospitals Complex, Ile-Ife. Osun State.

*Correspondence: Dr AM Owojuyigbe, Department of Anaesthesia and Intensive Care, Obafemi Awolowo University/Obafemi Awolowo University Teaching Hospitals Complex, Ile-Ife, Osun State. Email: muyelo2003@yahoo.com; ORCID - https://orcid.org/0000-0001-9342-8994.

\begin{abstract}
Background: The superimposition of the morbidity of cardiac diseases on the physiological demands of pregnancy could impact adversely on pregnancy outcomes. Therefore, contemporary information is for appropriate clinical management.

Objective: To determine the management outcomes of cardiac diseases in pregnancy at the Obafemi Awolowo University Teaching Hospitals Complex (OAUTHC), Ile-Ife.

Methods: A retrospective review of the hospital records of patients with cardiac diseases in pregnancy between January 2006 and December 2015 was conducted. The age, parity, gestational age at admission, NYHA class, clinical diagnosis, the results of investigations, complications of cardiac diseases, and maternal and foetal outcomes were recorded.

Results: There were 33 women with cardiac diseases in pregnancy and 11,352 deliveries within the period, giving an incidence of 2.9 per 1000. Further analysis was based on 24 women with complete records. The mean age of the patients was $29.2 \pm 5.5$ years. Twenty (83\%) of the women were Para 2 or less, while 13 (54\%) presented postpartum. The majority of the women (15; 62.5\%) had peripartum cardiomyopathy, while 17 (71\%) had NYHA Class III or IV disease. Thirteen (54\%) women had vaginal delivery. There were four perinatal and two maternal deaths, with a perinatal mortality rate of 166/1,000 total births and maternal mortality ratio of 8,333/100,000 live births.

Conclusion: Cardiac diseases in pregnancy are associated with high perinatal and maternal mortality rates at the OAUTHC, Ile-Ife. However, with early diagnosis and appropriate care, the majority of the patients had a satisfactory clinical outcome. Early presentation and advocacy to improve health-seeking behaviour are recommended.
\end{abstract}

Keywords: Cardiac diseases, Heart failure, Peripartal cardiomyopathy, Pregnancy. 


\section{Introduction}

The superimposition of the burden of cardiac diseases on the physiological demands of pregnancy could pose significant risks to foetomaternal well-being. The global incidence of morbidity and mortality related to cardiac diseases in pregnancy has been put at $0.1-4 \%$. [13] In the UK, the confidential enquiries into maternal deaths revealed that the overall rate of mortality from cardiac diseases has risen from 7.3 per million births (in the 1982-84 triennium) [4] to 22.7 per million births (in the 2003-05 triennium). [5] A majority of these deaths are due to acquired heart diseases.

In the developed world, the availability of diagnostic facilities and highly skilled manpower, culminating in early detection of cardiac pathology and timely medical and surgical interventions have resulted into increased survival of women with cardiovascular diseases up to reproductive age group. A multidisciplinary approach to the care of such women early in pregnancy has also resulted in better foeto-maternal outcomes.[6] This facilitates advanced planning of the mode of delivery among women with cardiac diseases in pregnancy. While vaginal delivery is desirable, specific instructions, such as the shortening of the second stage of labour may be necessary to limit exertion in some women. On the contrary, an elective caesarean section may be recommended for other women with cardiac disorders such as Marfan's syndrome with a dilated aortic root, Eisenmenger syndrome and dilated cardiomyopathy, in whom it is reasonably suspected that the heart would not tolerate the physiological stress of labour. This is in contrast to what obtains in developing nations.

Patients with cardiac disease in pregnancy carry high anaesthetic risk and outcome of pregnancy is often poor in resource-challenged settings.
This is due to poor health-seeking attitude, and late presentation, usually with severe complications and as emergencies. Notable among these complications are heart failure, arrhythmias, pulmonary oedema, stroke and cardiac arrest. [7] Foetal complications include prematurity, miscarriage, intrauterine growth restriction and foetal death. [8] The prognosis depends on the specific heart condition, the patient functional class and the degree of cardiac dysfunction. In anticipation of these complications, the patients are meticulously anti-coagulated in pregnancy and postpartum, as indicated. While on admission in pregnancy, during delivery and the puerperium, routine care is administered in the High Dependency Unit, with early recourse to the Intensive Care Unit whenever indicated.

Currently, there is limited data on peripartum and perinatal outcomes of cardiac diseases in pregnancy in resource-challenged countries. The present study aimed to determine the management outcome of cardiac diseases in pregnancy managed in a sub-urban tertiary hospital in a resource-challenged setting over ten years.

\section{Methods}

A retrospective study of all cardiac diseases in pregnancy admitted over 10 years between January 2006 and December 2015 was carried out. The Obafemi Awolowo University Teaching Hospitals Complex, Ile-Ife is a tertiary hospital located in the south-western part of Nigeria. The Obstetric Unit comprises of antenatal clinics, antenatal wards, labour wards, obstetric theatre and the postnatal wards. The hospital has specialist Consultant-led units in obstetrics and gynaecology, anaesthesiology, cardiology and paediatrics with accredited specialist training programs. The obstetricians receive to all the patients at the antenatal clinic and labour wards 
and determine those that will be admitted. A detailed history is obtained and the patient's disability graded according to the New York Heart Association (NYHA) classification. The usual investigations include full blood count, serum electrolytes and urea, voluntary testing for human immunodeficiency virus (HIV), and specific cardiac tests including electrocardiography (ECG), Chest X-Ray and echocardiogram.

Patients with cardiac diseases in pregnancy are seen at regular intervals at the antenatal clinic. Multidisciplinary care is ensured from the period of the first contact in pregnancy. The cardiologists assess all the patients and review treatment regimens.

In the present study, data were collected using a standardized proforma. The information collected included the age, parity, previous miscarriage, gestational age at admission, NYHA classification, type of cardiac disease, results of investigations, complications of the cardiac disease, mode of delivery, maternal outcome, foetal outcome, ASA classification, and anaesthetic technique.

The data were analysed using IBM-SPSS version 20.0 data presented as frequencies or proportions of the total. As the study was retrospective and completely anonymised such that the information is not attributable to any of the patients, research and ethics board approval was not sought.

\section{Results}

During the study period, 33 women presented with cardiac diseases in pregnancy or puerperium, and there were 11,352 deliveries in the hospital, giving an incidence rate of 2.9/1000 births. However, complete data were only available for 24 patents; further analysis was based on the 24 cases. The mean age of the women was $29.2 \pm 5.5$ years with only $5(21 \%)$ above 35 years of age as shown in Table I. Sixteen $(67 \%)$ of the patients were unbooked while 22 (92\%) were singleton pregnancies. More than half of the patients (54\%) presented in the puerperium while the rest presented antenatally or in labour. Twenty patients (83\%) were of low parity (parity $\leq 2$ ). Peripartum cardiomyopathy was the leading heart disease among the patients $(16 ; 66.7 \%)$ as sown in Table II.

Seventeen $(71 \%)$ patients presented with New York Heart Association Class III or IV disease (Figure 1). All the patients were evaluated with plain Chest X-ray, $9(38 \%)$ patients had electrocardiography while only $6(25 \%)$ could afford echocardiography.

In Table II, 13 (54\%) patients had a spontaneous vaginal delivery, while the remaining had Caesarean delivery. Of the 11 patients that had Caesarean delivery, six patients required general anaesthesia while five had neuraxial anaesthesia. Twenty-one per cent of the women required Intensive Care Unit (ICU) admission. Overall, twenty women made a satisfactory recovery and were discharged home. There were two maternal deaths, with a maternal mortality ratio of $8,333 / 100,000$ live births. The two patients developed peripartum cardiomyopathy on a background of poorly controlled chronic hypertension and were admitted in poor clinical condition intrapartum, having had unsupervised prolonged obstructed labour at unorthodox delivery centres. The two women deteriorated rapidly after delivery by Caesarean section and died within 24 hours of admission despite intensive care at the ICU. The outcome of the two patients who discharged themselves against medical advice due to lack of funds for further care was known.

There were 20 live births $(83.3 \%)$, 3 stillbirths $(12.5 \%)$ and one $(4.2 \%)$ early neonatal death (END) due to severe birth asphyxia. There was 
no congenital anomaly among the live births. The aetiology of the stillbirths could not be ascertained as they were all delivered before arrival in our facility. The perinatal mortality rate was $167 / 1,000$ in total births.

Table I: Socio-demographic and obstetric characteristics

\begin{tabular}{lll}
\hline Characteristics & Frequency & Percentage \\
\hline Age group (years) & & \\
$<19$ & 3 & 12.5 \\
$20-24$ & 0 & 0.0 \\
$25-29$ & 9 & 37.5 \\
$30-34$ & 7 & 29.2 \\
$\geq 35$ & 5 & 20.8 \\
& & \\
Level of education & & \\
None formal & 0 & 0.0 \\
Primary & 2 & 8.3 \\
Secondary & 14 & 58.3 \\
Tertiary & 8 & 33.3 \\
& & \\
Booking status & & \\
Booked & 8 & 33.3 \\
Unbooked & 16 & 66.7 \\
& & \\
Parity & & 37.5 \\
0 & 9 & 33.3 \\
1 & 8 & 12.5 \\
2 & 3 & 12.5 \\
3 & 3 & 4.2 \\
$\geq 4$ & 1 & \\
\hline
\end{tabular}

\section{Discussion}

Cardiac diseases in pregnancy are important contributors to maternal mortality. The incidence of heart diseases in pregnancy from the present study is 2.9 per 1000 , which tallies with previously reported global incidences of between 0.1 and $4 \%$. [1-3] The diagnoses were based largely on history and examination findings due to the lack of basic confirmatory investigations noted in the results.

However, there is a tendency to overestimate some cardiac diseases such as peripartum cardiomyopathy in the absence of required investigations such as the echocardiography. Peripartum cardiomyopathy was presumably the most common heart disease in this review with an incidence of 1 in 750 which is higher than the reported incidence of 1 in 3000 to 1 in 4000 births in the USA, and 1 in 1000 births in South Africa. [11, 12]

High incidence of up to $1 \%$ has been reported in Nigeria. [13] This high incidence of peripartum cardiomyopathy may not be unconnected to unrecognised and poorly treated hypertension in the pre-pregnancy and antepartum periods, traditional practices including hot baths in the puerperium and environmental influences. [14, 15] 


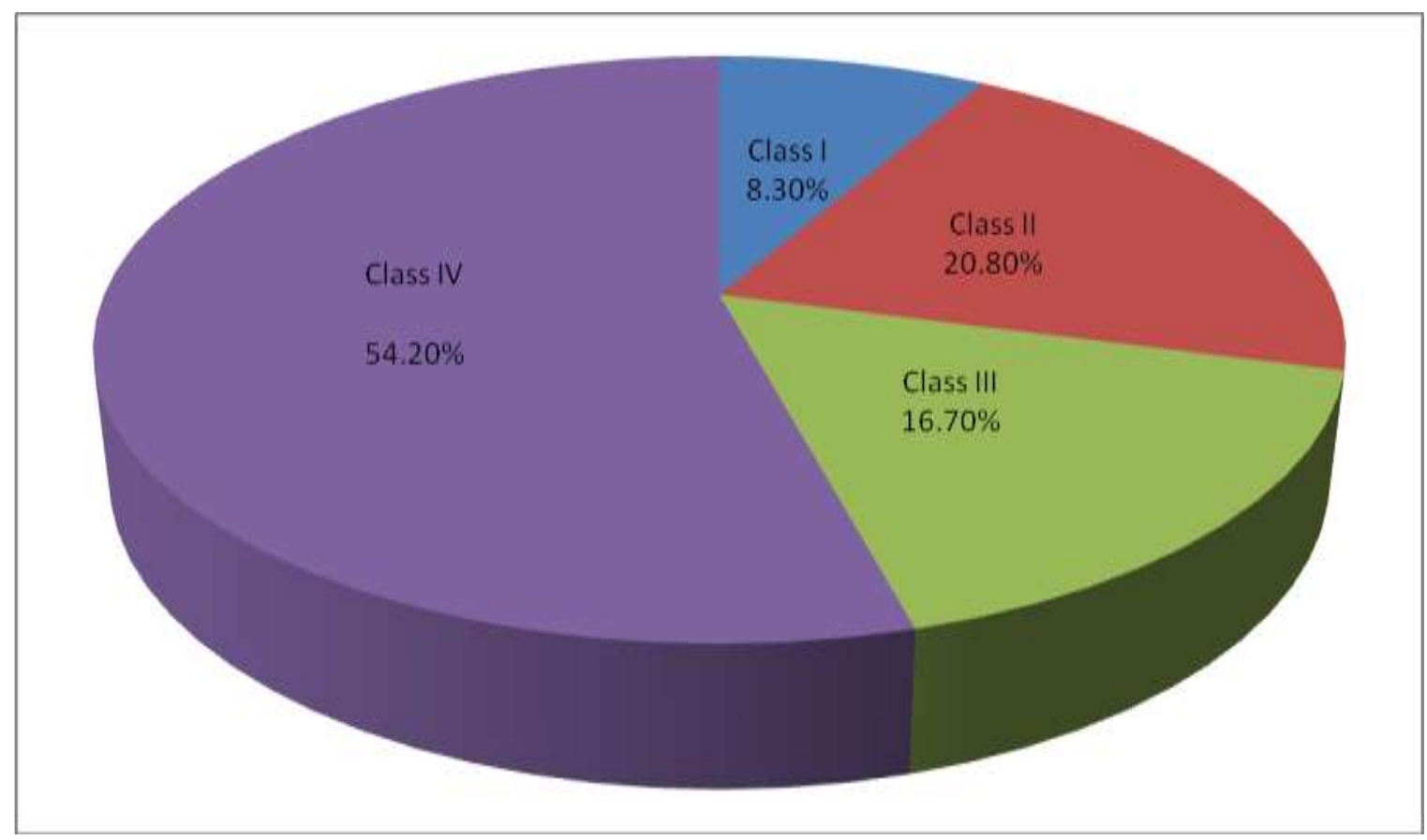

Figure 1: New York Heart Association classification of the patients at presentation

Cardiac failure secondary to hypertensive heart diseases was diagnosed in $25 \%$ of the patients. This emphasises the role of pre-conceptional care in chronic hypertensives and stabilisation before conception where indicated. Seventy-one per cent of the women presented in NYHA Class III or IV, implying late presentations to our centre following initial management in peripheral facilities or traditional birth homes in the antepartum and intrapartum periods. This reiterates the need for advocacy to improve health-seeking behaviour of pregnant women and to ensure early hospital presentation or referral to better-equipped facilities.

The two maternal deaths in this series were among women with cardiac disease in pregnancy, with superimposed morbidity of obstructed labour. Therefore, it is important to recommend specialised care for women with such morbidities, to formulate an appropriate care plan for the antenatal, intrapartum and postpartum periods. The role of skilled birth attendants in the supervision of their delivery process must also be emphasized. Considering the predominance of acquired heart diseases in this study as it is being reported globally also, adoption of lifestyle modifications to control chronic non-communicable diseases will be beneficial. [16] The risk of recurrence and probably more severe course should be mentioned when counselling women with peripartum cardiomyopathy. ${ }^{[17]}$ 
Table II: Obstetric characteristics and types of cardiac diseases

\begin{tabular}{|c|c|c|c|}
\hline \multicolumn{2}{|c|}{ Characteristics } & Frequency & Percentage \\
\hline \multicolumn{4}{|c|}{ Timing of presentation } \\
\hline \multicolumn{2}{|l|}{$<28$ weeks } & 2 & 8.3 \\
\hline \multicolumn{2}{|l|}{ 28-36 weeks } & 7 & 29.2 \\
\hline \multicolumn{2}{|l|}{$\geq 36$ weeks } & 2 & 8.3 \\
\hline \multicolumn{2}{|l|}{ Post-partum } & 13 & 54.2 \\
\hline \multicolumn{4}{|c|}{ Type of cardiac disease } \\
\hline \multicolumn{2}{|c|}{ Rheumatic Heart Disease } & 2 & 8.3 \\
\hline \multicolumn{2}{|c|}{$\begin{array}{l}\text { Peripartal } \\
\text { cardiomyopathy }\end{array}$} & 15 & 62.5 \\
\hline \multicolumn{4}{|c|}{ Disease } \\
\hline \multicolumn{2}{|c|}{ Congenital Heart Disease } & 1 & 4.2 \\
\hline \multicolumn{4}{|c|}{ Mode of delivery } \\
\hline \multicolumn{2}{|c|}{ Vaginal delivery } & 13 & 54.2 \\
\hline $\begin{array}{l}\text { Elective } \\
\text { section }\end{array}$ & Caesarean & 1 & 4.2 \\
\hline $\begin{array}{l}\text { Emergency } \\
\text { Section }\end{array}$ & Caesarean & 10 & 41.6 \\
\hline
\end{tabular}

\section{Conclusion}

The maternal and perinatal mortality rates recorded among the women with cardiac diseases in pregnancy at the OAUTHC, Ile-Ife calls for immediate concern. Strategies to identify women at risk early, adopt meticulous treatment of chronic hypertension preconception and ensure referral to the appropriate personnel for specialist care will improve the perinatal and maternal outcomes.

Authors' Contribution: OAM, AAT, SO and OTO participated in designing the study. OAM, $\mathrm{IAO}, \mathrm{SO}$, AIO and OTO did data collection and analysis and interpretation while OAM, AAT, AIO and OTO drafted the manuscript. All the authors approved the final version of the manuscript.

Conflict of Interest: None.

Funding: Self-funded.
Publication History: Submitted 06 October 2019; Accepted 17 February 2020.

\section{References}

1. Klein LL, Galan HL. Cardiac disease in pregnancy. Obstet Gynecol Clin N Am 2004; 31: 429-459.

2. Van Mook WNKA, Peeters L. Severe cardiac disease in pregnancy, Part II: impact of congenital and acquired cardiac disease during pregnancy. Curr Opin Crit Care 2005; 11: $435-448$.

3. Anandaraja S, Kothari SS, Bahl VK. Management of valvular heart disease during pregnancy. Ind Heart J 2005; 57: 101108.

4. Lewis G, (Editor): The Confidential Enquiry into Maternal and Child Health (CEMACH). Saving mothers' lives: Reviewing maternal 
deaths to make motherhood safer 2003-2005.

The 7th Report. London. CEMACH; 2009.

5. Steer PJ, Gatzoulius MA, Baker P. Heart Disease and Pregnancy. London. RCOG Press. 2006.

6. Burt CC, Dirbridge J. Management of cardiac disease in pregnancy. Cont. Edu Anaesthesia Crit Care and Pain 2009; 9: 4447.

7. Ruys TPE, Roos-Hesselink JW, Hall R, Subirana-Domenech MI, Grando-Ting J, Estensen M, et al. Heart failure in Pregnant women with cardiac disease: data from the ROPAC. Heart 2014; 100: 231-238.

8. Hammed AB, Montoro MN. Cardiac and Pulmonary Disease in Pregnancy. In: DeCherney AH, Nathan L, Goodwin TM, Laufer N (Editors). Current Diagnosis and treatment in Obstetrics and Gynaecology. 11 th Ed. McGraw-Hill Companies. New York. 2013: 465-473.

9. Karamermer $\mathrm{Y}$ and Roos-Hesselink JW. Pregnancy and adult congenital heart disease. Expert Rev Cardiovasc Ther 2007; 5: 859-869.

10. Sliwa K, Hilfiker-Kleiner D, Petrie MC, Mebazaa A, Pieske B, Buchmann E, et al. Current state of knowledge on aetiology, diagnosis, management, and therapy of peripartum cardiomyopathy: a position statement from the Heart Failure Association of the European Society of Cardiology Working Group on peripartum cardiomyopathy. Euro J Heart Failure 2010; 12: 767-778.
11. Ventura HO. Peripartum cardiomyopathy: clinical and therapeutic characteristics. J La State Med Soc 1991; 143: 45-48.

12. Desai D, Moodley J, Naidoo D. Peripartum cardiomyopathy: experiences at King Edward VIII Hospital, Durban, South Africa and a review of the literature. Trop Doct 1995; 25: 118-123.

13. Sanderson JE, Adesanya CO, Anjorin FI, Parry EH. Post-partum cardiac failure: Heart failure due to volume overload. Am Heart J 1979; 97: 613-621.

14. Demakis JG, Rahimtoola SH. Peripartum cardiomyopathy. Circulation 1971; 44: 964968.

15. Veille JC, Zaccaro D. Peripartum cardiomyopathy: summary of an international survey on peripartum cardiomyopathy. Am J Obstet Gynecol 1999; 181: 315-319.

16. Mosca L, Benjamin EJ, Berra K, Benzanson JL, Dolor RJ, Lloyd-Jones DM, et al. Effectiveness-based guidelines for the prevention of cardiovascular disease in women-2011 update: A guideline from the American Heart Association. Circulation. 2011; 123: 1243-1262.

17. Ramaraj R, Sorrell VL. Peripartum cardiomyopathy: causes, diagnosis, and treatment. Cleveland Clinic J Med 2009; 76; 289-296. 